\title{
Atributos físicos e químicos do solo cultivado com gravioleira, sob adubação orgânica e mineral
}

Physical and chemical attributes of soil cultivated with soursop, under organic and mineral fertilization

\author{
Altamiro Oliveira de Malta 1 \\ Msc. em Agronomia, Universidade Federal da Paraíba, Centro de Ciências Agrárias, Campus II \\ E-mail: altamirol@ig.com.br
}

Walter Esfrain Pereira 2

Prof. Dr. do Departamento de Ciências Fundamentais e Sociais, Universidade Federal da Paraíba, Centro de Ciências Agrárias, Campus II

E-mail: walterufpb@yahoo.com.br

\begin{abstract}
Mariana Neves Nóbrega Torres 3
Graduada em Agronomia, Universidade Federal da Paraíba, Centro de Ciências Agrárias, Campus II

E-mail: marianannobrega@gmail.com
\end{abstract}

\begin{abstract}
Alan Oliveira de Malta 4
Graduando em Agronomia, Universidade Federal da Paraíba, Centro de Ciências Agrárias, Campus II

E-mail: alan-oliveira@live.com

Edgley Soares da Silva 5

Prof. Msc. da Faculdade Roraimense de Ensino Superior, FARES, Boa Vista, RR

E-mail: edgley_agro2008@hotmail.com
\end{abstract}

Samuel Inocêncio Alves da Silva 6

Msc. em Agronomia, Universidade Federal da Paraíba, Centro de Ciências Agrárias, Campus II

E-mail: samuel-ufpb@hotmail.com

Resumo: A gravioleira é uma espécie frutífera que vem despertando interesse dentre os fruticultores do Brasil, no entanto, existem poucas informações relativas ao manejo da adubação. Sendo assim, o objetivo deste experimento foi avaliar os atributos físicos e químicos do solo de um pomar de gravioleira em função da adubação orgânica e mineral. Foi instalado um experimento em um pomar de gravioleira com 42 meses de idade entre os meses de janeiro a setembro de 2014, na cidade Areia-PB. O delineamento experimental foi em blocos casualizados, com sete tratamentos e quatro repetições. Os tratamentos utilizados foram: $\mathrm{T}_{1}=$ testemunha (sem adubação); $\mathrm{T}_{2}=$ adubação mineral (NPK); $\mathrm{T}_{3}=$ esterco de bovino; $\mathrm{T}_{4}=$ esterco de aves; $\mathrm{T}_{5}=$ adubação mineral + esterco de caprino; $\mathrm{T}_{6}=$ esterco de aves $+3 \mathrm{~kg}$ de pó de rocha; $\mathrm{T}_{7}=$ esterco de caprino. As variáveis de fertilidade e de física do solo avaliadas foram: $\mathrm{pH}$, fósforo, potássio, sódio, cálcio, magnésio, alumínio, hidrogênio + alumínio, carbono, matéria orgânica, densidade e porosidade do solo. Os dados foram submetidos à análise de variância e ao o teste de Tukey. A adubação com esterco bovino influenciou positivamente os teores de potássio, sódio, carbono e matéria orgânica do solo; $\mathrm{O}$ esterco de aves isolado e adicionado ao pó de rocha, manteve o $\mathrm{pH}$ do solo numa faixa que favorece a disponibilidade de nutrientes, além de fornecer maior teor de fósforo no solo; Nenhum dos tratamentos afetou os teores de cálcio, magnésio, alumínio, hidrogênio + alumínio, além da densidade e porosidade total do solo.

Palavras-chave: Annona muricata L.; Condicionador do solo; Disponibilidade de nutrientes. 


\begin{abstract}
The soursop is a fruiting species that has aroused interest among Brazilian fruit growers, however, there is little information on the management of fertilization. Thus, the objective of this experiment was to evaluate the physical and chemical attributes of the soil of a soursop orchard as a function of organic and mineral fertilization. An experiment was installed in a 42-month-old soursop orchard from January to September 2014, in the city of Areia-PB. The experimental design was in randomized blocks, with seven treatments and four replications. The treatments used were: $\mathrm{T} 1=$ control (without fertilization); $\mathrm{T} 2=$ mineral fertilization $(\mathrm{NPK}) ; \mathrm{T} 3=$ bovine manure; $\mathrm{T} 4=$ poultry manure; $\mathrm{T} 5=$ mineral fertilization + goat manure; $\mathrm{T} 6=$ poultry manure $+3 \mathrm{~kg}$ of rock dust; $\mathrm{T} 7=$ goat manure. Fertility and soil physical variables were evaluated: $\mathrm{pH}$, phosphorus, potassium, sodium, calcium, magnesium, aluminum, hydrogen + aluminum, carbon, organic matter, soil density and porosity. Data were submitted to analysis of variance and Tukey test. Fertilization with bovine manure influenced positively the potassium, sodium, carbon and organic matter contents of the soil; The poultry manure isolated and added to the rock powder, maintained the $\mathrm{pH}$ of the soil in a range that favors the availability of nutrients, besides providing higher phosphorus content in the soil; None of the treatments affected calcium, magnesium, aluminum, hydrogen + aluminum contents, as well as total soil bulk density and porosity.
\end{abstract}

Keywords: Annona muricata L.; Soil conditioner; Nutrient availability.

\title{
1 Introdução
}

O cultivo da gravioleira vem despertando interesse pelos agricultores, principalmente na região Nordeste do Brasil, graças a sua boa adaptação as condições edafoclimáticas. No entanto, por ser uma cultura ainda pouco estudada, faltam informações científicas a respeito do manejo da adubação, irrigação, controle de pragas, dentre outros (SÃO JOSÉ, 2014). E o solo por ser o grande fornecedor da maioria dos nutrientes essenciais das plantas, requer avaliação periódica, quanto à disponibilidade de elementos (FAQUIN, 2005).

Na fertilização dos solos, a combinação de adubos orgânicos com fertilizantes químicos, é uma pratica que vem sendo adotada por diversos produtores, pois além de aumentar a fertilidade do solo, promove incremento da matéria orgânica e atividade biológica, visando não só à melhoria das propriedades físicas e químicas do solo, mas, à redução dos quantitativos de adubos químicos aplicados (RICCI et al., 1995; RIZZI, 1998; BULLUCK et al., 2002).

Higashikawa et al. (2017) avaliaram adubação mineral, orgânica e organomineral, na fertilidade do solo, constataram que a adubação orgânica proporcionou melhoria nos atributos físico-químicos do solo em relação à adubação mineral, e que o efeito na fertilidade do solo, em relação à adubação organomineral, foi influenciada pelas doses de esterco de aves.

Gomes et al. (2005) trabalharam com adubação orgânica e mineral, nas características físicas e químicas de um solo vermelho amarelo, afirmaram que o uso do adubo químico promoveu a redução do tamanho médio dos agregados e a redução dos níveis de cálcio, 
magnésio e potássio do solo e aumento do nível de fósforo do solo. Observaram ainda que a utilização do composto orgânico propiciou aumento dos níveis de carbono orgânico, cálcio, magnésio, potássio e fósforo do solo.

Nogueira et al. (2012) estudaram os atributos químicos do solo, num projeto de fruticultura irrigada do Platô de Neópolis, Sergipe, sob cinco diferentes coberturas vegetais: coco, banana, manga, maracujá e vegetação nativa, concluíram que a aplicação de adubos minerais causa mudanças nos atributos químicos dos solos, com incrementos nos valores de $\mathrm{P}$, $\mathrm{K}, \mathrm{Ca}, \mathrm{Mg}, \mathrm{SB}, \mathrm{CTC}$ e V, em todas as áreas de frutíferas em relação à vegetação nativa.

Tendo em vista a importância de estudos voltados para o fornecimento de nutrientes ao solo, com também melhoria de sua estrutura, esse trabalho tem como objetivo avaliar os atributos físicos e químicos do solo, cultivado com gravioleira, sob adubação orgânica e mineral.

\section{Metodologia}

O experimento foi conduzido em pomar de gravioleiras da cultivar 'Morada', pertencente à Fazenda Quaty III, distrito de Santa Maria, localizado no município de Areia, PB. O referido município encontra-se inserido na mesorregião do Agreste paraibano e microrregião do Brejo paraibano, com as coordenadas geográficas de $6^{\circ} 57^{\prime} 42^{\prime \prime} \mathrm{S}$ e $35^{\circ} 41^{\prime} 43^{\prime \prime} \mathrm{W}$, a $618 \mathrm{~m}$ de altitude (GONDIM, 1999). O solo da área experimental é classificado como Latossolo Amarelo Distrófico. A vegetação nativa é de floresta subperenifólia e o relevo é fortemente ondulado (BRASIL, 1972).

O delineamento experimental foi em blocos casualizados, com sete tratamentos e quatro repetições, com duas plantas por parcela, no espaçamento de 5,0 m x 5,0 m. Sendo: $\mathrm{T}_{1}=$ testemunha (sem adubação); $\mathrm{T}_{2}=$ adubação química $(\mathrm{NPK}) ; \mathrm{T}_{3}=$ esterco de bovino; $\mathrm{T}_{4}=$ esterco de aves; $\mathrm{T}_{5}=\mathrm{NPK}+$ esterco de caprino, $\mathrm{T}_{6}=$ esterco de aves $+3 \mathrm{~kg}$ de pó de rocha e $\mathrm{T}_{7}=$ esterco de caprino. As gravioleiras no início da pesquisa estavam com 42 meses de idade, e o experimento foi realizado entre os meses de janeiro a setembro de 2014.

A adubação mineral foi realizada de acordo com a análise química do solo, levando em consideração os macronutrientes ( $\mathrm{P}$ e K). Quanto ao nitrogênio, a recomendação foi de acordo com Cavalcanti (2008), para a cultura da gravioleira em produção. Os atributos químicos do solo, na camada 0-20 $\mathrm{cm}$ de profundidade, apresentou os seguintes valores: $\mathrm{pH}=4,9 ; \mathrm{P}=3,67$ $\mathrm{mg} \mathrm{dm}{ }^{-3} ; \mathrm{K}^{+}=39,00 \mathrm{mg} \mathrm{dm}{ }^{-3} ; \mathrm{Na}^{+}=0,07 \mathrm{cmol}_{\mathrm{c}} \mathrm{dm}^{-3} ; \mathrm{H}^{+}+\mathrm{Al}^{3+}=8,0 \mathrm{cmol}_{\mathrm{c}} \mathrm{dm}^{-3} ; \mathrm{Al}^{3+}=0,85$ 
$\mathrm{cmol}_{\mathrm{c}} \mathrm{dm}^{-3} ; \mathrm{Ca}^{2+}=1,5 \mathrm{cmol}_{\mathrm{c}} \mathrm{dm}^{-3} ; \mathrm{Mg}^{2+}=1,35 \mathrm{cmol}_{\mathrm{c}} \mathrm{dm}^{-3} ;$ soma de bases de 3,02 $\mathrm{cmol}_{\mathrm{c}} \mathrm{dm}^{-3}$; $\mathrm{CTC}=11,02 \mathrm{cmol}_{\mathrm{c}} \mathrm{dm}^{-3} ; \mathrm{V}=27,40 \% ; \mathrm{m}=21,96 \%$ e matéria orgânica de $34,03 \mathrm{~g} \mathrm{~kg}^{-1}$.

A adubação orgânica foi realizada de acordo com análise química dos estercos, levandose em consideração apenas o teor de fósforo. Os teores de nutrientes dos estercos foram os seguintes: aves: 7,9 $\mathrm{g} \mathrm{kg}^{-1}$ de $\mathrm{N} ; 15,8 \mathrm{~g} \mathrm{~kg}^{-1}$ de P e 8,4 $\mathrm{g} \mathrm{kg}^{-1}$ de K. Caprino: $12,8 \mathrm{~g} \mathrm{~kg}^{-1}$ de N ;

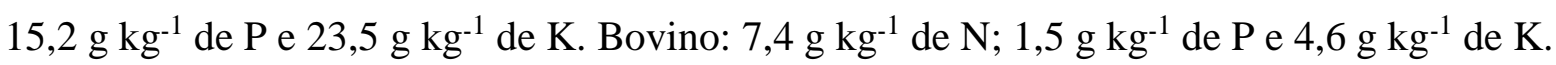

A calagem do solo foi realizada de acordo com a análise química do solo, aplicando-se calcário dolomítico ( $\mathrm{CaO}$ de 32,3\%; $\mathrm{MgO}$ de 19,3\%; $\mathrm{SiO}_{2}$ de 0,86\%) e gesso agrícola $(\mathrm{CaO}$ de $17,1 \% ; \mathrm{MgO}$ de $1,1 \% ; \mathrm{SiO}_{2}$ de 18,0$)$ na projeção da copa, sendo realizada em todos os tratamentos, inclusive na testemunha.

As variáveis de fertilidade e de física do solo avaliadas foram: $\mathrm{pH}$, fósforo, potássio, sódio, cálcio, magnésio, alumínio, hidrogênio + alumínio, carbono, matéria orgânica, densidade e porosidade total do solo. As analises foram feitas de acordo com metodologia da Embrapa (1999).

Os dados obtidos foram submetidos à análise de variância, utilizando-se até $5 \%$ de significância para o teste $\mathrm{F}$. As médias foram comparadas pelo teste de Tukey a 5\% de probabilidade. Utilizou-se o software SAS ${ }^{\circledR} 9.3$ (SAS, 2011) para as análises.

\section{Resultados e Discussão}

Houve efeito significativo dos tratamentos sobre o potencial hidrogeniônico $(\mathrm{pH})$, fósforo, potássio, sódio, carbono e matéria orgânica a $1 \%$ de probabilidade pelo teste $\mathrm{F}$ (Tabela 1). No entanto, não foi observado efeito significativo sobre as demais variáveis estudadas.

Tabela 1. Resumo da análise de variância do potencial hidrogeniônico $(\mathrm{pH})$, fósforo $(\mathrm{P})$, potássio $\left(\mathrm{K}^{+}\right)$, sódio

$\left(\mathrm{Na}^{+}\right)$, cálcio $\left(\mathrm{Ca}^{2+}\right)$, magnésio $\left(\mathrm{Mg}^{2+}\right)$, alumínio $\left(\mathrm{Al}^{3+}\right)$, hidrogênio + alumínio $\left(\mathrm{H}^{+}+\mathrm{Al}^{3+}\right)$, carbono $(\mathrm{C})$, matéria orgânica (MO), densidade (DS) e porosidade total (PT) em um pomar de gravioleira, sob a influência da adubação orgânica e mineral.

\begin{tabular}{cccccc}
\hline Fonte de variação & $\mathbf{G L}$ & $\mathbf{p H}$ & $\mathbf{P}$ & $\mathbf{K}^{+}$ & $\mathbf{N a}^{+}$ \\
\hline Blocos & 3 & 1,4806 & 1873,3002 & 664,2445 & 0,0002 \\
Tratamentos & 6 & $0,5077^{* *}$ & $7959,32^{* *}$ & $26221,79^{* *}$ & $0,0004^{* *}$ \\
Resíduo & 18 & 0,1062 & 1090,8860 & 846,5190 & 0,00007 \\
Total & 27 & 9,4014 & 73011,8208 & 174560,8174 & 0,0049 \\
& & & & & \\
\hline
\end{tabular}




\begin{tabular}{llllll}
\hline $\mathrm{CV}(\%)$ & - & 5,7 & 61,4215 & 27,8 & 14,2983 \\
& & & & & \\
\hline
\end{tabular}

\begin{tabular}{cccccc}
\hline Fonte de variação & $\mathbf{G L}$ & $\mathbf{C a}^{\mathbf{2 +}}$ & $\mathbf{M g}^{\mathbf{2 +}}$ & $\mathbf{A l}^{\mathbf{3 +}}$ & $\mathbf{H}^{\mathbf{+}+\mathbf{A l}^{\mathbf{3 +}}}$ \\
\hline Blocos & 3 & 6,8386 & 1,4489 & 0,1934 & 19,5784 \\
Tratamentos & 6 & $1,3722 \mathrm{~ns}$ & $0,6613 \mathrm{~ns}$ & $0,0772 \mathrm{~ns}$ & $4,3884 \mathrm{~ns}$ \\
Resíduo & 18 & 0,3970 & 0,3189 & 0,0274 & 1,4835 \\
Total & 27 & 35,8975 & 14,0567 & 1,5375 & 111,7700 \\
CV $(\%)$ & - & 20,0 & 25,0 & 73,0 & 16,0 \\
\hline
\end{tabular}

\begin{tabular}{cccccc}
\hline Fonte de variação & GL & C & MO & DS & PT \\
\hline Blocos & 3 & 19,5784 & 19,0448 & 0,0060 & 0,0007 \\
Tratamentos & 6 & $4,3884 * *$ & $75,4274 * *$ & $0,0108 \mathrm{~ns}$ & $0,0005 \mathrm{~ns}$ \\
Resíduo & 18 & 1,4835 & 30,7551 & 0,0065 & 0,0007 \\
Total & 27 & 111,7700 & 1063,2922 & 0,2013 & 0,0186 \\
\hline CV $(\%)$ & - & 16,0 & 18,0 & 5,7 & 6,0 \\
\hline
\end{tabular}

A calagem do solo influenciou positivamente o $\mathrm{pH}$, elevando-o de 4,9 para 6,3 (Figura 1A). A testemunha e o tratamento com adubação mineral, apresentaram os menores valores de pH com 5,37 e 5,35, respectivamente. Solos que receberam adubação orgânica, apresentaram elevação do pH. Este aumento pode estar relacionado com o incremento dos teores de matéria orgânica, devido a sua capacidade em liberar ou receber íons de $\mathrm{H}^{+}$(ALVES, 2012). Conforme Amaral (2004) a elevação do pH no solo, pela aplicação de estercos está relacionada à liberação

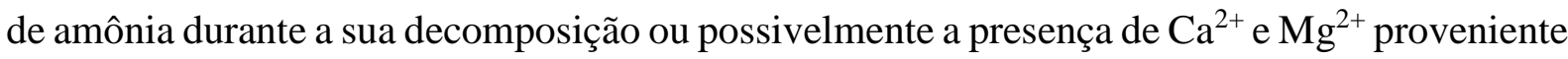
desse resíduo, que neutraliza e desloca elementos responsáveis pela acidez, como o $\mathrm{H}^{+}$.

O esterco de aves $\left(\mathrm{T}_{4}\right)$ e a mistura de esterco de aves mais pó de rocha $\left(\mathrm{T}_{6}\right)$, elevaram os teores de fósforo do solo, resultando em valores de 113,45 e 119,10 $\mathrm{mg} \mathrm{dm}^{-3}$, 
respectivamente (Figura 1B). Estes valores podem ser atribuídos a maior concentração de fósforo incorporado ao esterco e ao pó de rocha por ser um complexo mineral rico em fósforo. Segundo Andrade et al. (2003) o conteúdo total de P aumenta, quando o manejo favorece o incremento de carbono ou a utilização de fertilizantes, e diminui em sistemas intensivos de cultivo com baixa reposição de fósforo. Sistemas de manejo que promovem adição de matéria orgânica ao solo contribuem para a disponibilidade de P para as plantas (TORRES, 2014).

O maior teor de potássio do solo foi obtido no tratamento que continha esterco bovino $\left(\mathrm{T}_{3}\right.$ ), apresentando $278,10 \mathrm{mg} \mathrm{dm}^{-3}$ desse elemento (Figura 1C). A testemunha, por sua vez, apresentou os menores valores $\left(41,9 \mathrm{mg} \mathrm{dm}^{-3}\right)$, sendo que os demais tratamentos não diferiram estatisticamente. Alves (2012) relatou situação semelhante, em substratos que apresentavam as maiores doses de esterco, coincidindo com aumento do teor de potássio do solo para as mudas de atemoieira. Cavalcanti (2008) determina que valores de $120 \mathrm{mg} \mathrm{dm}^{-3}$ de potássio são admitidos como adequado às plantas.

Os teores de sódio apresentaram variação de 0,05 a $0,08 \mathrm{cmol}_{\mathrm{c}} \mathrm{dm}^{-3}$; os tratamentos com esterco bovino e esterco de aves, foram os que apresentaram os maiores teores no solo, 0,07 e $0,08 \mathrm{cmol}_{\mathrm{c}} \mathrm{dm}^{-3}$ respectivamente (Figura 1D). Malavolta et al. (1997) afirmam que solos com teores de sódio abaixo de $0,5 \mathrm{cmol}_{\mathrm{c}} \mathrm{dm}^{-3}$, são pobres no elemento. Mendes (2012) encontrou valor médio de $0,11 \mathrm{cmol}_{\mathrm{c}} \mathrm{dm}^{-3}$ de sódio, quando aplicado silício, cálcio e magnésio na primeira safra de atemoeira, sendo esses valores superiores aos obtidos neste trabalho.

Figura 1. Potencial hidrogeniônico (A), teores de fósforo (B), potássio (C) e sódio (D), em um pomar de gravioleira, sob influência da adubação orgânica e mineral. 

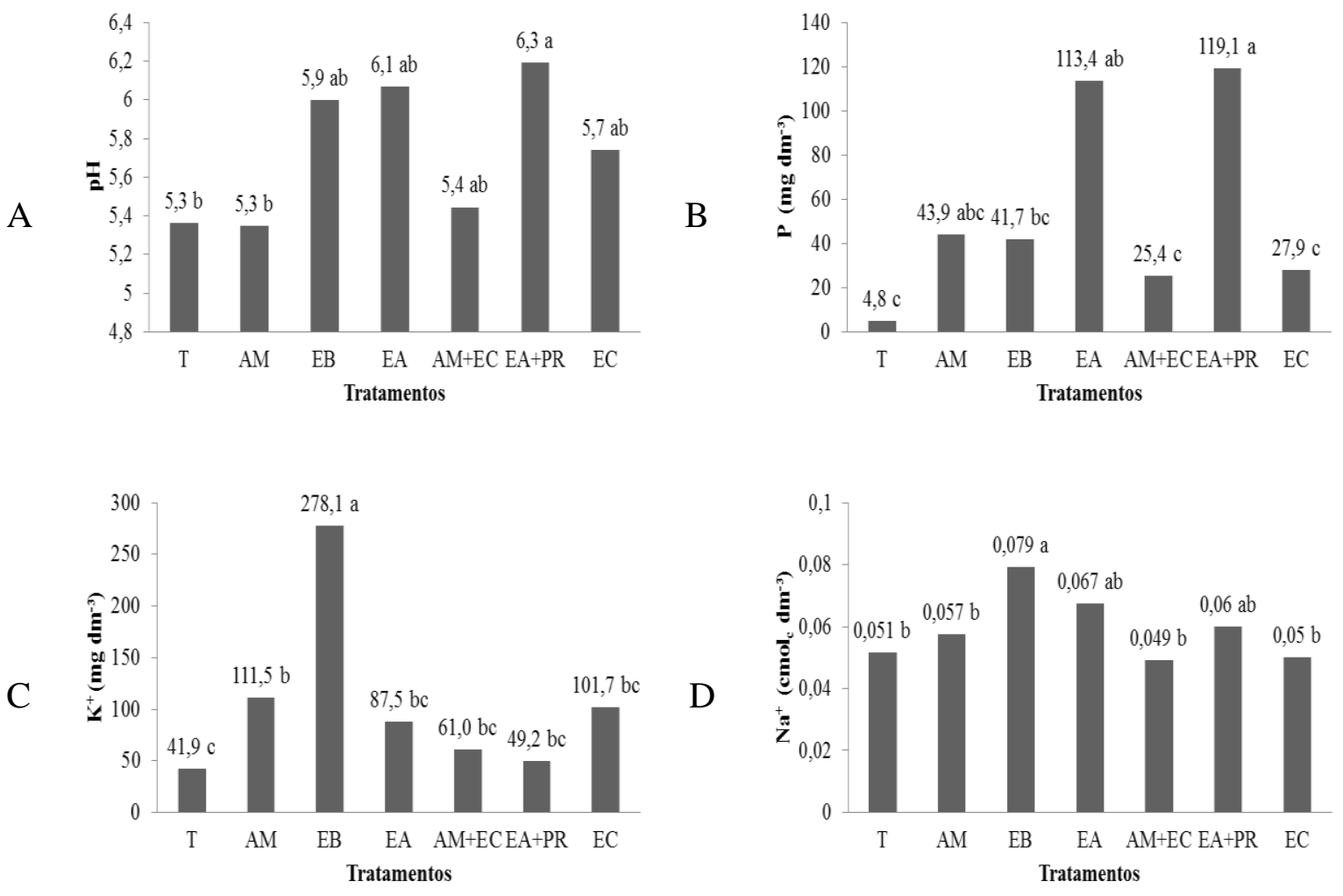

Médias seguidas pela mesma letra não diferem entre si pelo teste de Tukey a $5 \%$ de probabilidade. $\mathrm{T}=$ testemunha; $\mathrm{AM}=$ adubação mineral; $\mathrm{EB}=$ esterco bovino; $\mathrm{EA}=$ esterco de aves; $\mathrm{AM}+\mathrm{EC}=$ adubação mineral mais esterco caprino; $\mathrm{EA}+\mathrm{PR}=$ esterco de aves mais pó de rocha; $\mathrm{EC}=$ esterco caprino.

Com relação aos teores de cálcio, as médias variaram de 2,5 $\left(\mathrm{T}_{1}\right)$ a 3,8 $\left(\mathrm{T}_{3}\right) \mathrm{mg} \mathrm{dm}$, , provavelmente esse resultado esteja relacionado com a correção do solo realizada antes da aplicação dos tratamentos, sendo utilizado calcário dolomítico e gesso agrícola (Figura 2A). São José et al. (2014) relata a importância do cálcio para as anonáceas, pois este sendo componente da parede celular, faz parte de todos os tecidos da planta e é indispensável para o bom crescimento dos frutos, desde a fecundação até sua maturidade fisiológica, e quando ausente, pode acometer em rachaduras.

Os teores de magnésio do solo variaram de 1,6 ( $\left.\mathrm{T}_{1}\right)$ a 2,7 $\left(\mathrm{T}_{6}\right) \mathrm{mg} \mathrm{dm}^{-3}$ (Figura 2B). Esse resultado se assemelha ao do cálcio, onde, a calagem do solo antes da aplicação dos tratamentos, abasteceram o solo com esses cátions, justificando assim os resultados observados. Batista et al. (2003) testaram a omissão de macronutrientes no crescimento da gravioleira, perceberam que a altura da planta é reduzida com a omissão de magnésio.

O alumínio trocável foi reduzido de 0,85 inicialmente, a 0,45 $\left(\mathrm{T}_{1}\right)$ até $0,07\left(\mathrm{~T}_{6}\right) \mathrm{cmol}_{\mathrm{c}} \mathrm{dm}^{-}$ 3 (Figura 2C). Com a insolubilidade do alumínio, proporcionada pela prática da calagem, é possível verificar a neutralização dos seus efeitos tóxicos, aumentando o conteúdo do solo em cálcio, magnésio e até potássio (CAVALCANTE, 2000). Segundo Salvador et al. (2000) a 
baixa resposta das plantas às adubações pode ser atribuída, em parte, ao excesso de alumínio que, em solo com elevada acidez, pode tornar-se tóxico, causando graves anomalias ao sistema radicular. De acordo com Wilda et al. (2012) alta saturação por alumínio em subsuperfície é um fator que interfere no enraizamento de plantas e, consequentemente, resultam em menor absorção de água e nutrientes, diminuindo o potencial de rendimento das culturas.

Os valores de $\mathrm{H}^{+}+\mathrm{Al}^{3+}$ variaram de 9,09 a $6,41 \mathrm{cmol}_{\mathrm{c}} \mathrm{dm}^{-3}$ (Figura 2D), não diferindo estatisticamente entre os tratamentos. Este resultado se diferencia do observado por Costa et al. (2011) que em condições semelhantes fez correção do solo inicialmente e depois aplicou esterco bovino, obtendo redução significativa do $\mathrm{H}^{+}+\mathrm{Al}^{3+}$ em substrato contendo mudas de Eucalyptus citriodora $\mathrm{L}$.

Figura 2. Teores de cálcio (A), magnésio (B), alumínio (C) e hidrogênio + alumínio (D) do solo em um pomar de gravioleira, sob influência da adubação orgânica e mineral.

A
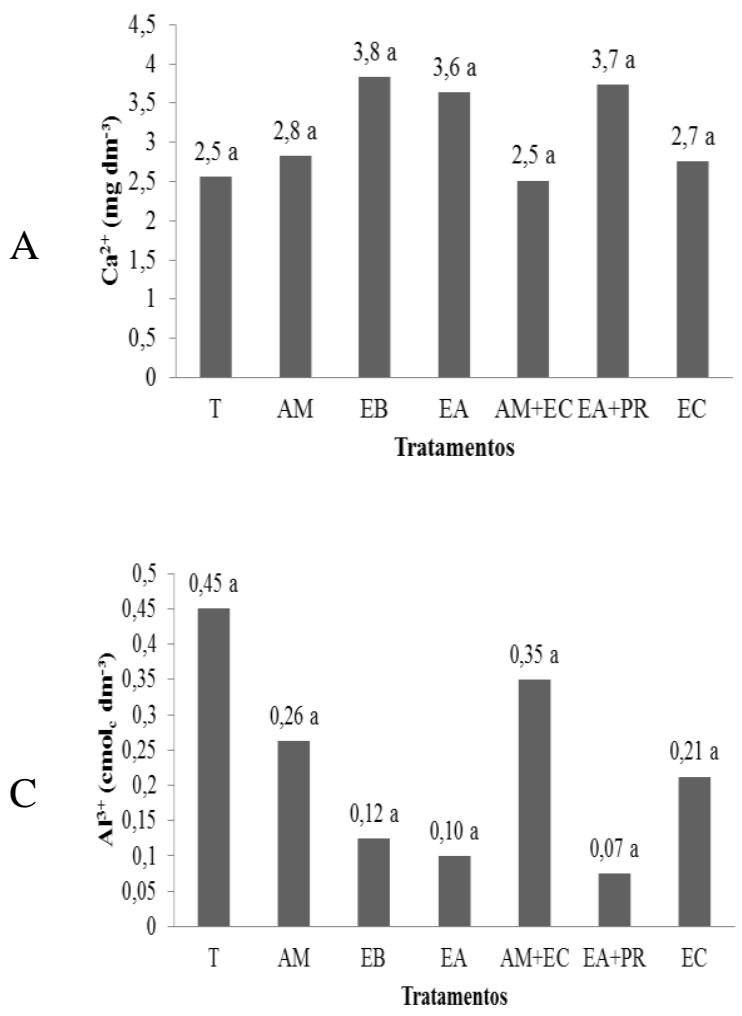

B
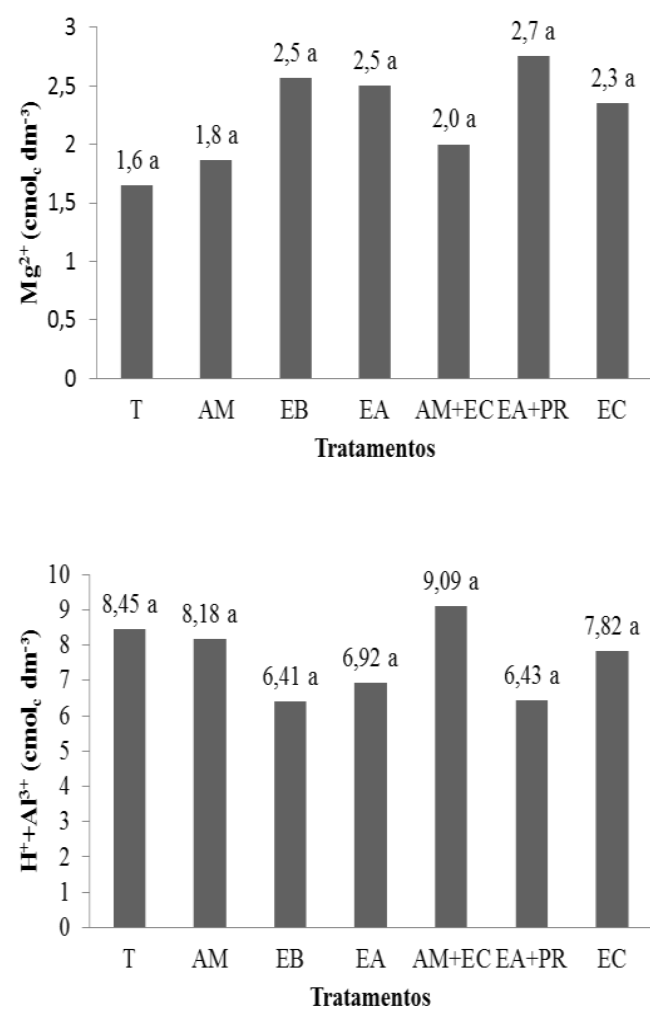

Médias seguidas pela mesma letra não diferem entre si pelo teste de Tukey a $5 \%$ de probabilidade. $\mathrm{T}=$ testemunha; $\mathrm{AM}=$ adubação mineral; $\mathrm{EB}=$ esterco bovino; $\mathrm{EA}=$ esterco de aves; $\mathrm{AM}+\mathrm{EC}=$ adubação mineral mais esterco caprino; $\mathrm{EA}+\mathrm{PR}=$ esterco de aves mais pó de rocha; $\mathrm{EC}=$ esterco caprino.

O tratamento com esterco bovino $\left(\mathrm{T}_{3}\right)$, apresentou a maior média $(22,7 \mathrm{~g} / \mathrm{kg})$ para os teores de carbono em relação aos demais tratamentos (Figura 3A). Segundo Malavolta (1981) os adubos orgânicos são caracterizados pelos elevados teores de matéria orgânica, nutrientes, 
inclusive o nitrogênio. Assim, adubações orgânicas normalmente resultam em elevação do nível de carbono no solo. Leite et al. (2003) relatam que o uso de esterco combinado com adubação mineral tem sido uma estratégia de manejo importante para melhoria da qualidade do solo, pois promove elevação do teor de carbono, quando se adiciona esterco em doses relativamente elevadas ou por tempo prolongado.

Os valores médios de matéria orgânica variaram de 25,7 ( $\left.\mathrm{T}_{1}\right)$ a 39,7 $\left(\mathrm{T}_{3}\right) \mathrm{g} \mathrm{dm}^{-3}$ (Figura 3B). De acordo com Kiehl (1985) a adição de matéria orgânica ao solo promove uma série de benefícios, que refletem sobre os rendimentos das culturas. Uma das principais vantagens é a incorporação ao solo de dois elementos químicos essenciais que não existem no material de origem (carbono e nitrogênio). Além desses, a matéria orgânica, também fornece $80 \%$ do fósforo total encontrado no solo, além de enxofre (PIRES \& JUNQUEIRA, 2001).

A maior densidade do solo (Figura 3C) foi observada quando se aplicou adubação mineral mais esterco caprino $\left(\mathrm{T}_{5}\right)\left(1,51 \mathrm{~g} \mathrm{~cm}^{-3}\right)$. Sendo a menor verificada no tratamento com esterco bovino $\left(\mathrm{T}_{3}\right)\left(1,35 \mathrm{~g} \mathrm{~cm}^{-3}\right)$. A elevação da densidade do solo prejudica o desenvolvimento das plantas, ocasionando aumento da resistência mecânica à penetração de raízes, altera a movimentação de água e nutrientes e a difusão de oxigênio e outros gases, levando ao acúmulo de gás carbônico na área radicular (MAPFUMO et al., 1998; ISHAQ et al., 2001).

A maior porosidade total (Figura 3D) foi observada nos tratamentos com adubação mineral $\left(\mathrm{T}_{2}\right)$, esterco bovino $\left(\mathrm{T}_{3}\right)$ e esterco de aves $\left(\mathrm{T}_{4}\right)$, ambos com $0,46 \mathrm{~m}^{-3} \mathrm{~m}^{-3}$. Em quanto a menor foi obtida na testemunha (sem adubação) $\left(T_{1}\right)\left(0,43 \mathrm{~m}^{-3} \mathrm{~m}^{-3}\right)$. De acordo com Laurindo et al. (2009) quanto maior o número de poros (macroporos) o solo apresentar, menor será sua densidade, e que a matéria orgânica tem o poder de flocular o solo, abrir espaços e, evitar a compactação, por isso, diminui a massa em relação ao volume aumentando a porosidade total do solo.

Figura 3. Teores de carbono (A), matéria orgânica (B), densidade do solo (C) e porosidade total (D) do solo em um pomar de gravioleira, sob influência da adubação orgânica e mineral 
A
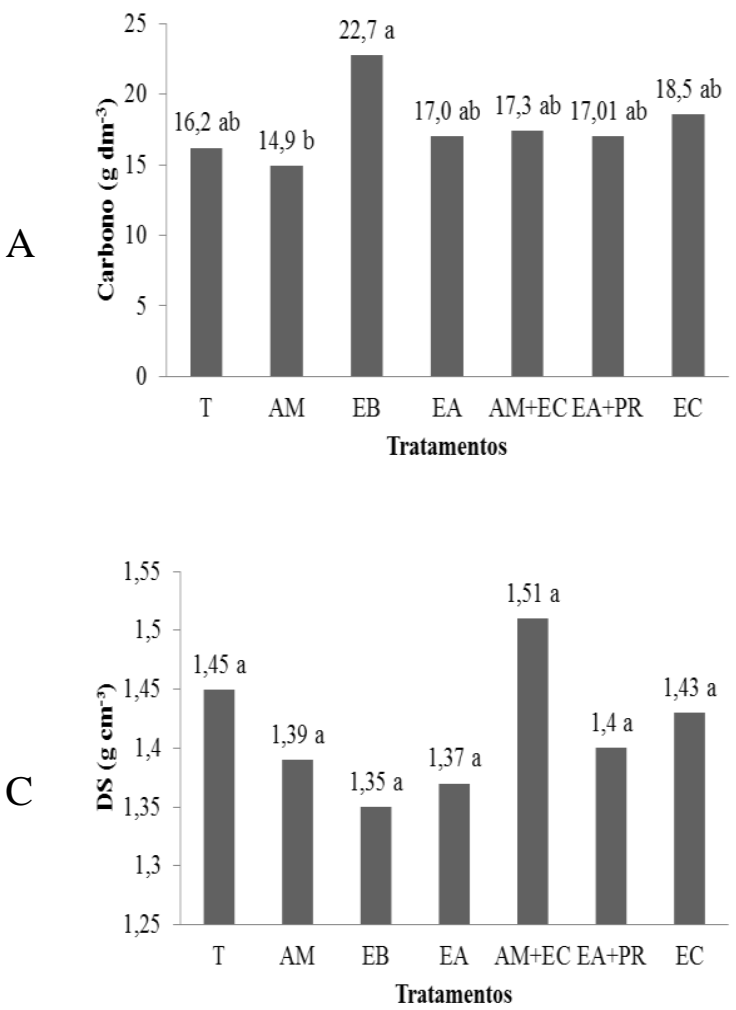

B

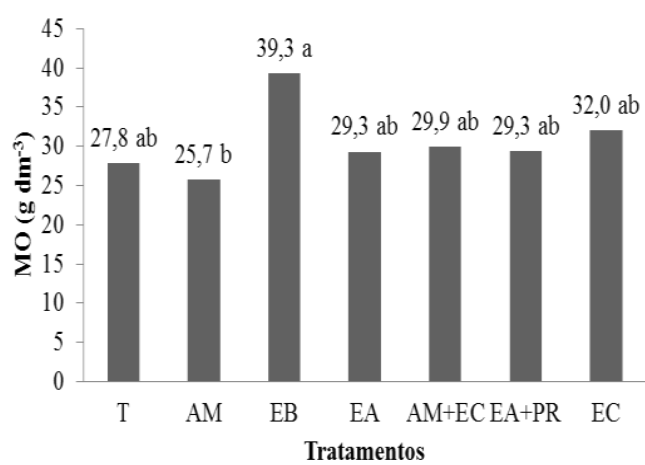

$\mathrm{D}$

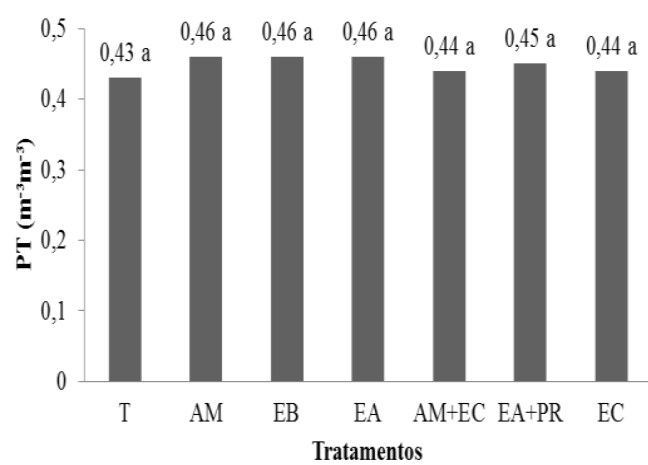

Médias seguidas pela mesma letra não diferem entre si pelo teste de Tukey a 5\% de probabilidade. $\mathrm{T}=$ testemunha; $\mathrm{AM}=$ adubação mineral; $\mathrm{EB}=$ esterco bovino; $\mathrm{EA}=$ esterco de aves; $\mathrm{AM}+\mathrm{EC}=$ adubação mineral mais esterco caprino; $\mathrm{EA}+\mathrm{PR}=$ esterco de aves mais pó de rocha; $\mathrm{EC}=$ esterco caprino.

\section{Considerações finais}

A adubação com esterco bovino apresenta-se como a mais indicada para a gravioleira 'Morada', pois influenciou positivamente os teores de potássio, sódio, carbono e matéria orgânica do solo;

$\mathrm{O}$ esterco de aves isolado e adicionado ao pó de rocha, manteve o $\mathrm{pH}$ do solo numa faixa que favorece a disponibilidade de nutrientes, e proporcionou maior teor de fósforo no solo;

Nenhum dos tratamentos afetou os teores de cálcio, magnésio, alumínio, hidrogênio + alumínio, além da densidade e porosidade total do solo.

\section{Referências}

ALVES, A. de S. Componentes e Fertilidade de Substratos na formação de Mudas de Atemoieira. 2012. 107 f. Dissertação (Mestrado em Manejo de Solo e Água), Centro de Ciências Agrárias, Universidade Federal da Paraíba, Areia 2012.

AMARAL, A. S.; ANGHINONI, I.; HINRICHS, R.; BERTOL, I. Movimentação de partículas de calcário no perfil de um cambissolo em plantio direto. Revista Brasileira de Ciência do Solo. 28:359-367, 2004. 
ANDRADE, F. V.; MENDONÇA, E. S.; ALVAREZ V., V. H.; NOVAIS, R. F. Adição de ácidos orgânicos e húmicos em Latossolos e adsorção de fosfato. Revista Brasileira de Ciência do Solo, 27:1003-1011, 2003.

BATISTA, M. M. F.; VIEGÁS, I. J. M.; FRAZÃO, D. A. C.; THOMAZ, M. A. A.; SILVA, R. C. L. Efeito da omissão de macronutrientes no crescimento, nos sintomas de deficiências nutricionais e na composição mineral em gravioleiras (Annona muricata L.). Revista Brasileira de Fruticultura, Jaboticabal, p. 315-318, 2003.

BRASIL. Ministério da Agricultura. Levantamento exploratório-reconhecimento de solos do estado da Paraíba. Rio de Janeiro: MA/SUDENE, 1972. 669 p. (Boletim Técnico, 15).

BULLUCK, L. R.; BROSIUS, M. G.; EVANYLO, K.; RISTAINO, J. B. Organic and synthetic fertility amendments influence soil microbial, physical and chemical properties on organic and conventional farms. Applied Soil Ecology, Amsterdam, v.19, n.2, p.147-160, 2002.

CAVALCANTE, L. F. Sais e seus problemas nos solos irrigados. 2000.71 f. Dissertação (Mestrado em Manejo do Solo e Água), Centro de Ciências Agrárias, Universidade Federal da Paraíba. 2000.

CAVALCANTI, F. J. A. (Coord.). Recomendações de adubação para o estado do Pernambuco ( $2^{\mathbf{a}}$ aproximação). 3. ed. Recife: Instituto Agronômico do Pernambuco-IPA, 2008. 212 p.

COSTA, F.G.; VALERT, S. V.; CRUZ, M. C. P. da; GONZALES, J. L. S. Esterco bovino para o desenvolvimento inicial de plantas provenientes de quatro matrizes de Corymbia citriodora. Scientia Florestalis, Piracicaba, v. 39, n. 90, p. 161-169, jun. 2011.

EMBRAPA. Sistema Brasileiro de Classificação de Solos. Brasília: Embrapa produção de Informação. Rio de Janeiro: Embrapa Solos, 1999. 412p.

FAQUIN, V. Nutrição Mineral de Plantas. Lavras: UFLA / FAEPE, 2005. p.: il. - Curso de Pós-Graduação “Lato Sensu” (Especialização) a Distância: Solos e Meio Ambiente.

GOMES, J. A.; SCAPIM, C. A.; BRACCINI, A. L.; VIDIGAL FILHO, P. S.; SAGRILO, E.; MORA, F. Adubações orgânica e mineral, produtividade do milho e características físicas e químicas de um Argissolo Vermelho Amarelo. Acta Sci. Agron. Maringá, v. 27, n. 3, p. 521$529,2005$.

GONDIM, A. W. A.: Geoeconomia e Agricultura do Brejo Paraibano: análise e avaliação. João Pessoa: Imprensa Universitária, 82p. 1999.

HIGASHIKAWA, F. S.; MENEZES JÚNIOR, F. O. G. Adubação mineral, orgânica e organomineral: efeitos na nutrição, produtividade, pós-colheita da cebola e na fertilidade do solo. Revista scientia agraria. vol. $18 \mathrm{n}^{\circ} .2$ Curitiba. p. 01-10, 2017.

ISHAQ, M.; IBRAHIM, M.; HASSAN, A.; SAEED, M.; L. A. L. R. Subsoil compaction effects on crops in Punjab, Pakistan: II. Root growth and nutrient uptake of wheat and 
sorghum. Soil and Tillage Research, Amsterdan, v.60, n.1, p.153-161, 2001.

KIEHL, E. J. Fertilizantes orgânicos. Agronômica Ceres, São Paulo, 492 p. 1985.

LAURINDO, M. C. O.; NÓBREGA, L. H. P.; PEREIRA, J. O.; MELO, D.; LAURINDO, E. L. atributos físicos do solo e teor de carbono orgânico em sistemas de plantio direto e cultivo mínimo. Engenharia na agricultura, viçosa - MG, V.17 N.5, Setembro / Outubro 2009.

LEITE, L. F. C.; MENDONÇA, E. S.; NEVES, J. C. L.; MACHADO P. L. O. A.; GALVÃO, J. C. C. Estoques totais de carbono orgânico e seus compartimentos em Argissolo sob floresta e sob milho cultivado com adubação mineral e orgânica. Revista Brasileira de Ciência do Solo, v. 27, p. 821-832, 2003.

MALAVOLTA, E.; VITTI, G. C.; OLIVEIRA, S. A. Avaliação do estado nutricional das plantas: princípios e aplicações. Piracicaba: Potafos, 1997. 201 p.

MALAVOLTA, E. Manual de química agrícola: adubos e adubação. São Paulo: Agronômica Ceres, 1981.

MAPFUMO, E.; CHANASYK, D. S.; BARON, V. S.; Forage growth and yield components as influenced by subsurface compaction. Agronomy Journal, Madison, v.90, n.4, p.805-812, 1998.

MENDES, H. T. A. Silicato de cálcio e magnésio na produção e nutrição mineral de atemoeira 'Gefner'. 2012. 92 f. Dissertação (Mestrado em Produção Vegetal no Semiárido), Universidade Estadual de Montes Claros, Janaúba, Minas Gerais. 2012.

NOGUEIRA, E. D.; C. JUNIOR. J. I. T.; VASCONCELLOS, M. C. B. Atributos químicos do solo sob diferentes coberturas Vegetais em áreas do platô de Neópolis-SE. Scientia Plena. Vol. 8, n'. 4, 2012.

PIRES, J. F.; JUNQUEIRA, A. M. R. Impacto da adubação orgânica na produtividade e qualidade das hortaliças. Horticultura Brasileira, v. 19, n. 2, p. 195, 2001.

RICCI, M. S. F.; CASALI, V. W. D.; CARDOSO, A. A.; RUIZ, H. A. Teores de nutrientes em duas cultivares de alface adubadas com composto orgânico. Pesquisa Agropecuária Brasileira, Brasília, v. 30, n. 8, p. 1035-1039, ago. 1995.

RIZZI, L.C.; RABELO, L.R.; MORINI FILHO, W.; SAVAZAKI, E.T.; KAVATI, R. Cultura do maracujá-azedo. Campinas: CATI, 1998, 54p. (Boletim Técnico, 235).

SALVADOR, J. O.; MOREIRA, A.; MALAVOLTA, E.; CABRAL, C. P. Influência do alumínio no crescimento e na acumulação de nutrientes em mudas de goiabeira. Revista Brasileira de Ciência do Solo, 24:787-796, 2000.

SÃO JOSÉ, A. R.; PRADO, N. B.; BONFIM, M. P.; REBOUÇAS, T. N. H.; MENDES, H. T. A. Marcha de absorção de nutrientes em anonáceas. Revista Brasileira de Fruticultura. v. 36, edição especial, e., p. 176-183, fev 2014. 
STATISTICAL ANALYSIS SYSTEM INSTITUTE, SAS - Institute SAS/STAT software 2011, CD-ROOM.

TORRES, M. N. N. Teores de N, P e K nas folhas de gravioleira 'morada' (Annona muricata $\mathrm{L}$.) e propriedades químicas do solo em função da adubação química e orgânica. Areia, Centro de Ciências Agrárias, Universidade Federal da Paraíba, 2014, 39 p. (Trabalho de conclusão de curso).

WILDA, L. R. M.; RESENDE, A. V.; CUNHA, T. F.; LACERDA, J. J. J.; LIMA, G. J. O. Condições de Acidez Subsuperficial de Solos Cultivados Para a Produção de Grãos no Cerrado do Brasil Central. Anais... FERTBIO 2012. 